\title{
Prolonged constant load cycling exercise is associated with reduced gross efficiency and increased muscle oxygen uptake
}

\begin{tabular}{|r|l|}
\hline Journal: & Scandinavian Journal of Medicine and Science in Sports \\
\hline Manuscript ID: & SJMSS-O-248-15.R1 \\
\hline Manuscript Type: & Original Article \\
\hline Date Submitted by the Author: & n/a \\
\hline Complete List of Authors: & $\begin{array}{l}\text { Hopker, James; University of Kent, } \\
\text { O'Grady, Ciaran; University of Kent, } \\
\text { Pageaux, Benjamin; Université de Bourgogne, }\end{array}$ \\
\hline Keywords: & $\begin{array}{l}\text { Cycling Efficiency, Lactate Threshold, Maximal Oxygen Uptake, Endurance } \\
\text { Performance, Muscle Efficiency }\end{array}$ \\
\hline
\end{tabular}


Prolonged constant load cycling exercise is associated with reduced gross efficiency and increased muscle oxygen uptake

James G. Hopker ${ }^{1}$, Ciaran O’Grady ${ }^{1}$, Benjamin Pageaux ${ }^{1,2}$

1. Endurance Research Group, School of Sport and Exercise Sciences, University of Kent, UK.

2. Laboratoire INSERM U1093, Université de Bourgogne, Faculté des Sciences du Sport - UFR STAPS, Dijon, France.

Running Head: Oxygen consumption during cycling

\section{Corresponding Author:}

Dr. James Hopker

School of Sport and Exercise Sciences

University of Kent

Chatham Maritime

Kent

UK

Tel. +44 (0)1634 888814

Fax. $+44(0) 1634888809$

Email. J.G.Hopker@kent.ac.uk 


\section{ABSTRACT}

This study investigated the effects of prolonged constant load cycling exercise on cycling efficiency and local muscle oxygen uptake responses. Fourteen well trained cyclists each completed a $2 \mathrm{~h}$ steady state cycling bout at $60 \%$ of their maximal minute power output to assess changes in gross cycling efficiency (GE) and muscle oxygen uptake $\left(\mathrm{mV}_{2}\right)$ at time points 5, 30, 60, 90 and 120 min. Near-infrared spatially resolved spectroscopy (NIRS) was used to continually monitor tissue oxygenation of the Vastus Lateralis muscle, with arterial occlusions (OCC) applied to assess $m \dot{\mathrm{VO}} \mathrm{O}_{2}$. The half-recovery time of oxygenated hemoglobin $\left(\mathrm{HbO}_{2}\right)$ was also assessed pre and post the $2 \mathrm{~h}$ cycling exercise by measuring the hyperaemic response following a $5 \mathrm{~min}$ OCC. GE significantly declined during the 2 h cycling bout $(18.4 \pm 1.6$ to $17.4 \pm 1.4 \%$; $P$ $<0.01$ ). Conversely, $\mathrm{mVO}_{2}$ increased, being significantly higher after 90 and $120 \mathrm{~min}$ than at $\min 5\left(+0.04 \mathrm{mlO}_{2} \cdot \mathrm{min}^{-1} \cdot 100 \mathrm{~g}^{-1} ; P=0.03\right)$. The half-recovery time for $\mathrm{HbO}_{2}$ was increased comparing pre- and post- the $2 \mathrm{~h}$ cycling exercise $(+7.1 \pm \pm 19 \mathrm{~s})$, albeit not significantly $(d: 0.48 ; P=0.27)$. This study demonstrates that GE decreases during prolonged constant load cycling exercise and provides evidence of an increased $\mathrm{mV்}_{2}$, suggestive of progressive mitochondrial or contractile inefficiency.

Keywords: Cycling efficiency, lactate threshold, maximal oxygen uptake, endurance performance, muscle efficiency 
1 INTRODUCTION

2 Cycling gross efficiency (GE) has been demonstrated to be a key determinant of

3 cycling performance (Hopker et al., 2013). GE is defined as the ratio of power output

4 to power input from measures of oxygen uptake $\left(\dot{\mathrm{VO}}_{2}\right)$ and carbon dioxide $\left(\dot{\mathrm{VCO}}_{2}\right)$

5 during steady state cycling (Hopker et al., 2012). Sustained moderate intensity

6 exercise has been shown to reduce GE, via an unexplained increase in $\dot{\mathrm{VO}}_{2}$ measured

7 at the mouth (Hagan et al., 1992; Hagberg et al., 1978; Passfield \& Doust, 2000), and

8 subsequently reduce high intensity cycling performance (Passfield \& Doust, 2000).

9 However, both the rate of decline and the underlying mechanisms are yet to be fully

10 established.

Oxidative phosphorylation is the main process by which ATP is produced under

13 aerobic conditions. Mitochondrial efficiency has been shown to be an important

14 component in exercise efficiency (Fernstrom et al., 2007), and so changes in the efficiency of oxidative phosphorylation will therefore affect cycling efficiency. Key questions remain unanswered regarding the efficiency of energy transfer within the

17 mitochondria and the possible role of the uncoupling of oxidative phosphorylation.

18 Uncoupling accounts for around $50 \%$ of resting oxygen consumption in rodent muscle

19 (Tonkonogi et al., 1998), and has been seen to increase by $18 \%$ after prolonged

20 exhaustive exercise in human skinned muscle fibers (Whipp \& Wasserman, 1969).

21 Further in a recent study, muscle uncoupling protein content (UCP3) has been

22 negatively correlated with work efficiency in a cohort of mixed-ability cyclists

23 (Mogensen et al., 2006). Another potential mechanism responsible for an apparent

24 additional $\dot{\mathrm{VO}}_{2}$ slow component (Poole et al., 1994) during prolonged constant

25 intensity exercise might be related to muscle contractile inefficiency. Specifically, 
26 during prolonged exercise above the lactate threshold it has been suggested that the

$27 \quad \dot{\mathrm{V}}{ }_{2}$ slow component might be the product of an increased phosphate cost of power

28 production (Rossiter et al., 2002; Cannon et al., 2014). Indeed, previous research has

29 demonstrated a close relationship between muscle and whole body $\dot{\mathrm{V}}_{2}$ measured via

30 pulmonary oxygen consumption (Poole et al., 1992). Therefore, an increase in

31 mitochondrial uncoupling and muscle $\dot{\mathrm{VO}}_{2}\left(\mathrm{mV}_{2}\right)$ during prolonged cycling exercise

32 has the potential to increase the $\dot{\mathrm{V}}_{2}$ from constant load exercise, and consequently

33 reduce cycling efficiency.

34

35 Near-infrared spectroscopy (NIRS) can provide information about the changes in

36 tissue oxygenation at rest and during exercise (Ferrari et al., 2011) from the oxygen

37 dependent absorption characteristics of infrared light. This non-invasive technique

38 therefore allows continuous monitoring of the dynamics of tissue oxygenation.

39 Indeed, NIRS has been used to provide information about relative changes in

40 oxygenated haemoglobin/myoglobin $\left(\mathrm{HbO}_{2}\right)$, deoxygenated haemoglobin/myoglobin

$41(\mathrm{HHb})$, and total haemoglobin or blood volume (tHb). Resultantly, NIRS has been

42 used to measure skeletal muscle oxygenation (Chuang et al., 2002) and provide an

43 estimate of blood flow (De Blasi et al., 1997; Nioka et al., 2006). Moreover, repeated

44 arterial occlusions have been used both during and after exercise to assess muscle

45 oxygen consumption as an index of mitochondrial function (Van Beekvelt et al.,

46 2001). During arterial occlusion an absolute value for muscle $\mathrm{O}_{2}$ consumption can be

47 calculated, under the assumption that $\mathrm{tHb}$ remains constant (due to the occlusion),

48 from the decreasing slope of $\mathrm{HbO}_{2}$. The disassociation of oxygen molecules from

49 oxyhaemoglobin/myoglobin reflects the requirement of oxidative phosphorylation, 
and therefore will be indicative of the tightness of mitochondrial coupling and changes in the rate ATP consumption per unit of power production.

52

53 The aim of this study was to determine the relationship between whole body measures of GE calculated from pulmonary $\dot{\mathrm{VO}}_{2}$, and $\mathrm{mV}_{2}$ (measured via NIRS) during $2 \mathrm{~h}$ constant load cycling exercise at $60 \%$ of maximal minute power output. We load cycling exercise.

62

\section{MATERIALS AND METHODS}

Fourteen well-trained male cyclists (mean \pm SD: age $30 \pm 14$ years, mass $66 \pm 11 \mathrm{~kg}$, $\dot{\mathrm{V}} \mathrm{O}_{2 \max } 73 \pm 2 \mathrm{~mL} \cdot \mathrm{kg}^{-1} \cdot \mathrm{min}^{-1}$, maximum minute power output [MMP] $319 \pm 15 \mathrm{~W}$ ) volunteered to participate in the study. All participants had a minimum of two years training and racing experience, and were in preparation for a full competitive season. The study was completed with full ethical approval from the local institutional ethics committee according to the Declaration of Helsinki standards. All cyclists provided written informed consent prior to participating. 


\section{Study Design and Experimental Procedures}

77 Participants visited the exercise testing laboratory on two separate occasions in a 78 euhydrated state. During visit 1 participants undertook an incremental exercise test 79 (see Maximal incremental test for more details) for the identification of $\dot{\mathrm{V}}_{2 \max }$ and

80 MMP. The protocol used at Visit 2 is shown in Figure 1, and consisted of participants 81 undertaking $2 \mathrm{~h}$ of constant load cycling at $60 \%$ maximal minute power output (see 282 hours cycling test for more details) to assess changes in $\mathrm{GE}$ and $\dot{\mathrm{V}}_{2}$. Prior to, and 83 immediately following the $2 \mathrm{~h}$ cycling bout, participants completed a $6 \mathrm{~s}$ maximal 84 isokinetic sprint test at set cadences of 60, 90 and 120 rev.min ${ }^{-1}$ (see Sprint tests for 85 more details). All tests were completed on an electromagnetically braked cycle 86 ergometer (Schoberer Rad Messtechnik GmbH, Jülich, Germany). An electric cooling 87 fan was used to cool participants for the whole duration of the $2 \mathrm{~h}$ constant load 88 cycling exercise. Participants were also provided with water to drink adlibitum during

89 both visits. Visits were conducted on non-concurrent days, with participants instructed

90 to refrain from any exercise in the day prior to testing and intense exercise in the two 91 days prior, not to consume caffeine $3 \mathrm{~h}$ before each visit.

***INSERT FIGURE 1 HERE***

93

\section{Maximal incremental test}

The maximal incremental test started with a 10 min warm-up at $100 \mathrm{~W}$, after which required cycling power output increased by $5 \mathrm{~W}$ every $15 \mathrm{~s}$ until the participant reached volitional exhaustion (operationally defined as a cadence of $<60$ revolutions/min for $>5 \mathrm{~s}$, despite strong verbal encouragement). Respiratory gas exchange data were assessed using an online gas analyzer (Metalyzer 3B, CORTEX Biophysik GmbH, Leipzig, Germany) throughout the test, by use of a facemask 
100 covering the nose and mouth. Participant's $\dot{\mathrm{V}} \mathrm{O}_{2 \max }$ was assessed as the highest $\dot{\mathrm{V}} \mathrm{O}_{2}$

101 that was attained during a $60 \mathrm{~s}$ period in the test. MMP was assessed as being the

102 highest average $60 \mathrm{~s}$ power output during the test. Following the maximal incremental exercise test, participants were familiarized with the testing procedures used during visit 2. This consisted of familiarization with muscle occlusions, practice $6 \mathrm{~s}$ sprint trial, and a $10 \mathrm{~min}$ bout of cycling at the target $2 \mathrm{~h}$ power output in order to determine 106 preferred cadence.

\section{2-hour cycling test}

108

Following a $10 \mathrm{~min}$ warm-up at $100 \mathrm{~W}$ and the sprint tests, participants cycled at 60 \% MMP continuously for $120 \mathrm{~min}$. During this time, expired air was collected for one minute using non-diffusible gas bags (Hans - Rudolph, USA), at time points 5, 30, 60, 90 and 120 min, and were analyzed immediately following collection using a Servomex 5200 gas analyzer (Servomex, Crowborough, East Sussex) by the procedures outlined by Hopker et al. (2012). During the final $20 \mathrm{~s}$ of gas collection, and whilst the cyclist continued to pedal at the required rev. $\min ^{-1}$, an arterial occlusion (see NIRS below) was applied to the right leg to determine local muscle oxygen uptake $\left(\mathrm{mV}_{2}\right)$. This procedure allows controlling for the confounding effects of changes in blood flow on $\mathrm{mV}_{2}$. Throughout the 120 min of cycling, subjects were required to maintain a constant self-selected cadence (range: $80-88$ rev. $\min ^{-1}$ ), which was determined during Visit 1 . Heart rate was recorded continuously throughout the exercise test (S810i, Polar Electro Oy, Finland).

Blood lactate concentration was measured using a fingertip capillary blood sample and was taken during exercise at the same time points as the expired gases and NIRS measurements. Blood samples were analyzed using a Biosen C-Line (EKF 
124 Diagnostic, London, UK). RPE measurements were also taken at the same time points

125 using the Borg 6-20 scale (Borg, 1998).

\section{Calculation of cycling efficiency}

127 Cycling efficiency was calculated as the ratio of work done to energy expended

128 during the sampling minute in the form:

129 Gross Efficiency \% $=($ Work accomplished/Energy Expenditure $) \times 100$

130 In order to establish the 'Work accomplished', the mean power recorded during the

131 same period as the respiratory collection was determined and converted into

132 kcal.min ${ }^{-1}$ via the following equation:

133 'Work accomplished' $\left(\right.$ kcal.min $\left.{ }^{-1}\right)=$ Power $(\mathrm{W}) \times 0.01433$

134 Energy expenditure was calculated from the 1 min respiratory collection to ascertain

$135 \dot{\mathrm{VO}}_{2}$ and Respiratory Exchange Ratio (RER). The calorific equivalent of $\mathrm{O}_{2}$ was then

136 determined from the corresponding RER according the data of Peronnet and

137 Massicotte (1991):

138 'Energy expenditure' $\left(\mathrm{kcal} \cdot \mathrm{min}^{-1}\right)=\dot{\mathrm{VO}}_{2}\left(\mathrm{~L}_{\mathrm{min}} \mathrm{m}^{-1}\right) \times \mathrm{kcal} \cdot \mathrm{L}^{-1}$ of $\mathrm{O}_{2}$

$140 \quad$ Near-infrared Spectroscopy

141 Muscle oxygenation and consumption in the right Vastus Lateralis (VL) was

142 continuously monitored using wireless spatially resolved dual-wavelength

143 spectrometers (Portamon, Artinis Medical Systems, BV, the Netherlands). The small

144 unit measures $83 \times 52 \times 20 \mathrm{~mm}$ and weighs $84 \mathrm{~g}$, including the battery. The device has

145 three pairs of diodes emitting light of wavelengths 760 and $850 \mathrm{~nm}$. Resultantly it is 
146 possible to detect combined concentration changes in the chromophores haemoglobin

$147 \quad(\mathrm{Hb})$ and myoglobin $(\mathrm{Mb})$. The distance between light source and detector was $40 \mathrm{~mm}$.

148 The inability to measure absolute chromophore concentrations can be accommodated

149 for by using Spatially Resolved Spectroscopy (SRS). The Portamon device utilizes

150 three light sources in a spatially resolved configuration, distanced 30,35 , and $40 \mathrm{~mm}$

151 from the one light receiver. A differential path-length factor of 4.0 was assumed

152 during all tests. The gradient of light attenuation allows a deeper more muscle-biased

153 measurement with less interference from superficial skin and fat layers. SRS is also

154 insensitive to light scattering, allowing the diffusion equation for light transport to be

155 used to yield an absolute measure of tissue oxygen saturation (TSI\%). Using these

156 methods, changes are reported from an arbitrary baseline value taken prior to the start 157 of exercise.

158

159 The NIRS optode was situated on the cyclist's right leg, over the belly of the VL

160 muscle and $10 \mathrm{~cm}$ proximal to the knee joint on a line between the greater trochanter

161 of the femur and the lateral epicondyle. Skinfold thickness was measured at the

162 location of the probes using a skinfold caliper. The skinfold thickness was $11.1+2.8$

163 mm. To ensure the optodes and detector did not move relative to the subject's skin,

164 the device was fixed into position using surgical tape, and then secured with a

165 bandage.

166 A pressure cuff (Hokanson SC12D; Bellevue, WA, USA) was secured around the

167 thigh and proximal to the NIRS device. During occlusions, the pressure cuff was

168 rapidly (<0.3 s) inflated to $300 \mathrm{mmHg}$ for $5 \mathrm{~min}$ using a semi-automated inflation

169 system (Hokanson E20; Bellevue, WA, USA). This was used as a measure of baseline 
$170 \mathrm{mV}_{2}$ following the warm-up, but prior to the $2 \mathrm{~h}$ constant load cycling exercise.

171 Following release of the cuff, the hyperaemic response was used to assess the half-

172 recovery time and re-oxygenation rate at baseline. Finally, 5 min after release of the

173 occlusion and resolution of the hyperaemic response, baseline NIRS measurements were taken in the two minutes immediately prior to the start of exercise. The NIRS

175 data were collected wirelessly at $10 \mathrm{~Hz}$, then for the purposes of further analysis, a

176 10-point moving average was applied.

177

178

179

180

182

183

184

185

186

187

188

189

190

191

192

193 both the influx of oxygenated arterial blood and the continued $\mathrm{O}_{2}$ consumption during

194 recovery (Chance et al., 1992). The half time recovery of $\mathrm{HbO}_{2}$ (s) was calculated 
195 from maximum deoxygenation at the end of the 5 min occlusions (pre- and post- $2 \mathrm{~h}$

196 exercise) to $50 \%$ of the maximum re-oxygenation during hyperaemia (Chance et al,

197 1992). The reoxygenation rate $\left(\Delta \mathrm{HbO}_{2}\right.$ in $\left.\mu \mathrm{M} \cdot \mathrm{s}^{-1}\right)$ was calculated as the rate of

198 increase in $\mathrm{HbO}_{2}$ during the initial $3 \mathrm{~s}$ after cessation of the occlusion both pre- and

199 post- $2 \mathrm{~h}$ constant load cycling exercise. This variable reflects the initial inflow of

$200 \mathrm{HbO}_{2}$ over a fixed time period following the release of the occlusion and is therefore

201 not influence by the magnitude of the hyperaemic response. Thus, the half time

202 recovery of $\mathrm{HbO}_{2}$ and re-oxygenation rates were used to provide an indication of the

203 recovery of vascular components and the continued oxygen consumption following

204 exercise cessation. We speculated that in the presence of increased mitochondrial

205 uncoupling and reduced cycling efficiency, there is likely to be a slowed half time

206 recovery of $\mathrm{HbO}_{2}$ and re-oxygenation rate.

*** INSERT FIGURE 2 HERE***

208 Sprint Tests

209 To assess muscle fatigue via maximal voluntary cycling power output, prior to, and

210 immediately following the $2 \mathrm{~h}$ constant load cycling exercise, participants were asked

211 to perform three maximal sprints, each of $6 \mathrm{~s}$ followed by $60 \mathrm{~s}$ active recovery (with

212 no resistance). Sprints were performed at three fixed cadences $(60,90$ and 120

213 rev. $\mathrm{min}^{-1}$ ) using the isokinetic mode of the electromagnetically braked cycle

214 ergometer. Peak $1 \mathrm{~s}$ power output was obtained from each sprint in order to assess the

215 maximal voluntary power producing capability of the exercising muscles and

216 consequently highlights the presence of exercise-induced muscle fatigue (i.e. decrease

217 in the ability to produce maximal power). 
219 Prior to all data analysis, data was checked for normality of distribution. Repeated 220 measures analysis of variance (ANOVA) with least significant difference unadjusted 221 post hoc analysis used to analyze data from the $2 \mathrm{~h}$ constant load cycling exercise. 222 Differences in sprint power output at the cadences of 60,90 and 120 rev.min ${ }^{-1}$ were 223 assessed using two-way repeated measures ANOVA. Effect sizes were calculated 224 using partial eta squared $\left(\eta_{\mathrm{p}}{ }^{2}\right)$ and were defined as small, moderate or large based 225 upon .02, .13 and .26, respectively (Cohen et al., 1998). The difference in half226 recovery time and reoxygenation rate of $\mathrm{HbO}_{2}$ pre- to post- $2 \mathrm{~h}$ constant load cycling 227 exercise were assessed using a paired t-test, with Cohen's $d$ effect sizes being defined 228 as $0.2,0.5$ and 0.8 for small, medium and large effects respectively (Cohen et al., 229 1998). Statistical analyses were conducted using IBM SPSS Statistics 22 (IBM®, 230 Armonk, NY), and a $P<0.05$ was used as the criteria for detection of significance in 231 all cases. Data are reported as mean and standard deviation (mean $\pm \mathrm{SD}$ ) unless 232 specified otherwise.

233

234

235

236

237

238

\section{RESULTS}

\section{Cardiorespiratory measurements}

Mean cycling power output was $192 \pm 9 \mathrm{~W}$ with mean cadence being $84 \pm 1 \mathrm{rev} \cdot \mathrm{min}^{-1}$ during the $2 \mathrm{~h}$ constant load cycling exercise. Both submaximal $\dot{\mathrm{VO}}_{2}$ and $\dot{\mathrm{VCO}}_{2}$ increased significantly over the period of cycling $\left(\dot{\mathrm{V}}_{2}=\eta_{\mathrm{p}}{ }^{2}: 0.40 ; P=<0.01\right.$; Figure 3c; $\dot{\mathrm{V} C O}{ }_{2}=\eta_{\mathrm{p}}{ }^{2}: 0.34 ; P=0.01$; Figure 3d). GE significantly declined during the $2 \mathrm{~h}$ constant load cycling exercise $\left(\eta_{\mathrm{p}}{ }^{2}: 0.38 ; P<0.01\right.$; Figure 3a) from an initial value of $18.4 \pm 1.6 \%$ at $\min 6$ to $17.4 \pm 1.4 \%$ at minute 120 . RER significantly declined between 90 and 120 min of constant load cycling exercise $\left(\eta_{\mathrm{p}}{ }^{2}: 0.28 ; P=0.01\right.$; Figure 3b). $\dot{V}_{\mathrm{E}}$ significantly increased during the $2 \mathrm{~h}$ cycling period with time points 90 and 
245120 min being greater than time points 5 and $30 \min \left(\eta_{\mathrm{p}}{ }^{2}: 0.49 ; P<0.01\right.$; Figure $\left.3 \mathrm{e}\right)$.

246 Heart rate significantly increased over the $2 \mathrm{~h}$ constant load cycling exercise, being

247 higher at 90 and 120 min than minute $5\left(\eta_{\mathrm{p}}{ }^{2}: 0.42 ; P<0.05\right.$; Figure $\left.3 \mathrm{f}\right)$.

248

***INSERT FIGURE 3 HERE***

249

Blood lactate and perceived exertion

250 Blood lactate concentration rose significantly from baseline after 5 min of cycling $251\left(\eta_{\mathrm{p}}{ }^{2}: 0.37 ; P=0.01\right.$, Figure $\left.3 \mathrm{~g}\right)$, stayed unchanged between 5 and $30 \mathrm{~min}$ and then 252 reduced significantly between $60(P=0.03)$ and $90 \min (P=0.04)$. At the end of the 253 cycling exercise, blood lactate was significantly higher than baseline $(P<0.01)$, but 254 not different from any of the other time points. Even though the required work rate 255 was held constant at $60 \%$ MMP, perceived exertion rose continuously throughout the $2562 \mathrm{~h}$ constant load cycling exercise. RPE at all measured time points was significantly 257 higher than the previous $\left(\underline{\eta}_{\mathrm{p}}^{2}: 0.73 ; P<0.05\right.$, Figure $\left.3 \mathrm{~h}\right)$.

\section{NIRS measurements}

260 The responses of NIRS parameters during the $2 \mathrm{~h}$ constant load cycling exercise are

261 shown in Figure 4. There was no significant change in $\mathrm{HbO}_{2}\left(\eta_{\mathrm{p}}{ }^{2}: 0.20 ; P>0.05\right.$;

262 Figure $4 \mathrm{a})$, however $\mathrm{HHb}$ increased significantly $\left(\eta_{\mathrm{p}}{ }^{2}: 0.25 ; P=0.02\right)$, with values at 26390 and 120 min being statistically higher than at min 5 (Figure $4 \mathrm{~b}$ ). tHb increased 264 steadily over time after 30 min of constant load cycling with time points of 60,90 and 265120 min being significantly greater than 5 and $30 \min \left(\eta_{\mathrm{p}}{ }^{2}: 0.30 ; P<0.04\right.$; Figure $\left.4 \mathrm{c}\right)$.

266 There was a trend for a reduction in TSI\% levels over the $2 \mathrm{~h}$ constant load cycling

267 exercise $\left(\eta_{\mathrm{p}}^{2}: 0.15 ; P=0.20\right.$, Figure $\left.4 \mathrm{~d}\right) . \underline{\text { As can be seen in the typical } \mathrm{mV} \mathrm{O}_{2}} \underline{\text { trace, }}$ 
268 figure 2, during the occlusion $\mathrm{O}_{2} \underline{\mathrm{Hb} \text { decreased, } \mathrm{HHb} \text { increased and } \mathrm{tHb} \text { remained }}$

269 stationary, indicating that the blood flow was occluded. Resting $\mathrm{mV} \mathrm{O}_{2}$ was $0.04 \pm 0.02$

270

$\underline{\mathrm{mlO}_{2}} \cdot \underline{\min ^{-1} \cdot 100 \mathrm{~g}^{-1} \text { and demonstrated a } 7.5 \pm 3.8 \text { fold increase after } 6 \text { min cycling at }}$

271

$60 \% \mathrm{MMP} . \mathrm{mV}_{2}$ increased further during the $2 \mathrm{~h}$ constant load cycling exercise,

272

being significantly higher after $90 \underline{(10.0 \pm 5.5 \text { fold increase })}$ and $120 \mathrm{~min}(\underline{10.3 \pm 6.2}$

273

fold increase) than at $\min 5\left(\eta_{\mathrm{p}}{ }^{2}: 0.29 ; P=0.03\right.$, Figure 5a). There was a trend for

274

both the half-recovery time ( $d: 0.48 ; P=0.27$; Figure $5 \mathrm{~b})$, and reoxygenation rate $(d$ :

$2750.60 ; P=0.11$; Figure $5 \mathrm{c}$ ) of $\mathrm{HbO}_{2}$ to be slower following occlusion after the $2 \mathrm{~h}$

276 constant load cycling exercise.

$277 * * *$ INSERT FIGURE 4 \& 5 HERE***

278 Sprint tests

279 There was no interaction effect between 6-s sprint time point (i.e. pre vs. post $2 \mathrm{~h}$ of

280 cycling) and sprint cadence $\left(\eta_{\mathrm{p}}{ }^{2}: 0.09 ; P=0.29\right)$. Regardless of cadence, sprint power

281 output was significantly lower at each cadence following the $2 \mathrm{~h}$ constant load cycling

282 exercise $\left(\eta_{\mathrm{p}}{ }^{2}: 0.51 ; P=0.04\right.$; Figure 6$)$. However, the reduction in GE was not related

283 to the decline in 6-s sprint power output at any cadence $(P>0.05)$.

284

***INSERT FIGURE 6 HERE*** 


\section{DISCUSSION}

286 This study used NIRS to investigate the relationship between local muscle and whole 287 body physiological responses to prolonged constant load cycling exercise. The main 288 findings of this study was that GE declined significantly during $2 \mathrm{~h}$ constant load 289 cycling exercise in accordance with the findings of previous studies (Hagan et al., 290 1992; Hagberg et al., 1978; Passfield \& Doust, 2000), despite maintenance of constant 291 power output and cadence. The physiological data recorded during the constant load 292 exercise trial may provide some answers to the origins of the reduction in efficiency 293 recorded. GE is the ratio of work accomplished to energy expenditure and expressed 294 295 as a percentage (Hopker et al., 2012), where work accomplished is determined by the mean cycling power output of the corresponding data-sampling period. Energy expenditure is determined by the oxygen cost of the exercise multiplied by the caloric equivalent per liter of oxygen determined from the corresponding RER. The reduction

298 of GE seen in the current study was associated with a significant increase in the 299 oxygen cost of the exercise, i.e. the emergence of a $\dot{\mathrm{VO}}_{2}$ slow component (see Figure 300 3c). Previous research has demonstrated that increases in fat metabolism, ventilation, 301 lactate metabolism, and body temperature cannot account for the increased oxygen 302 cost of work after sustained moderate-intensity cycling exercise (Hagan et al., 1992, 303 Hagberg et al., 1978). The present data support this conclusion. RER decreased by 3040.02 units (0.96-0.94) across the $2 \mathrm{~h}$ period constant load cycling exercise and so there 305 were minimal changes in substrate metabolism. There was a significant increase in 306 pulmonary ventilation (mean $16 \mathrm{~L} \cdot \mathrm{min}^{-1}$ ) during the $2 \mathrm{~h}$ constant load cycling 307 exercise but this was estimated to only increase $\dot{\mathrm{VO}}_{2}$ by a negligible $29 \mathrm{~mL} \cdot \mathrm{min}^{-1} \mathrm{O}_{2}$ 308 (Aaron et al., 1992). Blood lactate was significantly higher during the cycling bout 309 than at baseline, but once elevated to $\sim 3 \mathrm{mmol} . \mathrm{L}^{-1}$ at $\min 5$, there were no further 
310 increases even though GE continued to decline. Unfortunately no measures of core

311 temperature were taken during the current study, although Passfield and Doust (2000)

312 demonstrate that following an initial rise, core body temperature reaches a plateau

313 during constant load cycling at $60 \% \dot{\mathrm{V}}_{2 \text { peak. Therefore, we are confident that changes }}$

314 in core temperature significantly affected gross efficiency in the current study.

315

316 It is possible that the cause of this reduction in efficiency is related to changes at the

317 local muscle level (Gonzalez-Alonso et al., 1998). Interestingly the reduction in

318 efficiency does not seem to be related to the loss in maximal muscle function assessed

319 by the $6 \mathrm{~s}$ sprints before and after the cycling bout. However, in support of previous

320 findings by Passfield and Doust (2000), there were reductions in gross efficiency and

321 maximal cycling power output of a similar magnitude $(\sim 10 \%)$. Therefore further

322 studies should clarify the hypothetical relationship between changes in GE and

323 muscle fatigue induced by prolonged constant load cycling exercise.

324

325 NIRS provides the ability to investigate the balance between $\mathrm{O}_{2}$ supply and utilization

326 within the exercising muscle (Hamaoka et al., 1996). As shown in Figure 4, there was

327 a relative increase in $\mathrm{HHB}$ and $\mathrm{tHb}$ during the exercise test, indicating that there was

328 an increase in blood volume coupled with increased local muscle deoxygenation

329 during the constant load cycling exercise. $\mathrm{HbO}_{2}$ remained statistically unchanged

330 throughout the cycling bout. The general trend for progress local Vastus Lateralis

331 muscle desaturation (as shown by the $\mathrm{HHb}$ and TSI\%) to occur as the trial progressed

332 suggests a greater metabolic demand rather than $\mathrm{O}_{2}$ supply to exercising muscle.

333 Therefore, mitochondrial oxygen consumption could be assumed to have

334 progressively increased during the $2 \mathrm{~h}$ constant load cycling exercise. It is important 
335 to note that muscle oxygenation (TSI\%) does not directly reflect $\mathrm{mVO}_{2}$, but reflects

336 the balance between oxygen supply and consumption (Hamaoka et al., 1996). A more

337 robust measure of $m \dot{\mathrm{V}} \mathrm{O}_{2}$ is performed using arterial occlusions to control inflow and

338 outflow of blood to the limb, i.e. to limit changes in blood volume (Van Beekvelt et

339 al., 2001). Most previous studies have used occlusions of the upper limb (e.g. Van

340 Beekvelt et al., 2001), with few using arterial occlusions on large muscle groups i.e.

341 the legs (Brizendine et al., 2013; Nagasawa, 200; Nioka et al., 2006). To the author's

342 knowledge, this is the first study to use occlusions of the quadriceps muscle during

343 whole-body dynamic exercise to evaluate $\mathrm{m}_{\mathrm{V}} \mathrm{O}_{2}$.

344

$345 \mathrm{mV}_{2}$ increased steadily over the course of the $2 \mathrm{~h}$ constant load cycling exercise,

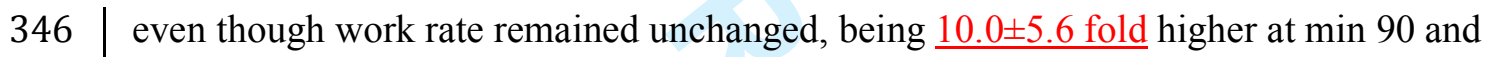

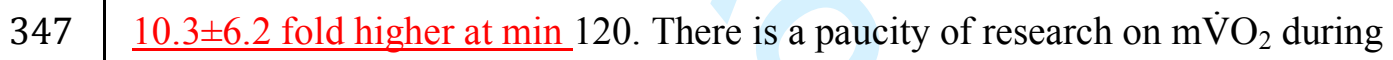

348 cycling exercise. To our knowledge, the only previous research using NIRS to

349 determine $\mathrm{mV}_{2}$ via arterial occlusions of the quadriceps was performed after, rather

350 than during exercise (Brizendine et al., 2013; Nagasawa et al., 2008), making direct

351 comparisons difficult. We are aware of only one previous study to use arterial

352 occlusions during exercise to determine $\mathrm{mV}_{2}$. Van Beekvelt et al. (2001)

353 demonstrated a $\sim 6$ fold increase in $\mathrm{mV}_{2}$ during a $10 \%$ isometric MVC of the

354 forearm. Submaximal cycling at $70 \% \dot{\mathrm{VO}}_{2} \max$ has been shown to require $\sim 20 \%$ MVC

355 (Lollgen et al., 1980) and so our $\sim 10$ fold magnitude of increase in $\mathrm{mV}_{2}\left(\mathrm{mlO}_{2} \cdot \mathrm{min}^{-}\right.$

$\left.356 \quad{ }^{1} .100 \mathrm{~g}^{-1}\right)$ is, unsurprisingly, higher than the forearm data.

357

358 The reasons for the progressive increase in $\mathrm{mV}_{2}{ }_{2}$ despite no change in exercise

359 intensity are unclear. One possibility is an alteration of the ratio between 
360 mitochondrial ADP phosphorylation and oxygen consumption (P/O ratio), which

361 reflects the efficiency of oxidative phosphorylation. Specifically, back leak of protons

362 across the inner membrane without driving ATP-synthase would reduce the $\mathrm{P} / \mathrm{O}$ ratio,

363 and thus increase uncoupling. Increased content or activation of uncoupling protein-3

364 (UCP3) appear to be important in mediating this process (Mogensen et al., 2006).

365 Alternatively, the rise in $\mathrm{mV}_{2}$ could be caused by some mitochondrial ATP

366 generation being used to reduce ROS generation within the cell (Brand, 2000). A high

367 proton motive force that drives efficient ATP synthesis is associated with an

368 additional ROS production. Proton leak across the mitochondrial membrane without

369 driving ATP production may therefore assist in limiting the oxidative damage

370 associated with high levels of ROS generated during the prolonged cycling exercise

371 (Sahlin et al., 2010).

372

373 While it is possible that the energetic cost of exercise might increase if the $\mathrm{O}_{2}$ cost of

374 ATP production increases with progressive mitochondrial uncoupling, an alternative

375 possibility is that the ATP cost of contraction changes during prolonged exercise. In

376 support of this proposition Cannon et al. (2014), have demonstrated that there is an

377 increased phosphate cost of power production during constant load moderate intensity

378 bilateral knee extensor exercise. Cannon et al. (2014) suggest that an increase in ATP

379 turnover rate and $\dot{\mathrm{VO}}_{2}$ during constant load exercise is consequent to a rise in

380 contractile inefficiency due to muscle fatigue (Rossiter et al., 2002). Indeed the

381 reduction of maximal voluntary cycling power at 60,90 and $120 \mathrm{rev} \cdot \mathrm{min}^{-1}$ shown in

382 the current study after $2 \mathrm{~h}$ constant load cycling indicates the presence of muscle

383 fatigue. As prolonged cycling exercise is known to induce both peripheral and central

384 components of muscle fatigue (Lepers et al., 2000; Lepers et al., 2002), we are 
385 confident that at least part of the decrease in maximal voluntary cycling power is due

386 to presence of peripheral fatigue, i.e. fatigue produced by changes at or distal to the

387 neuromuscular junction (Gandevia et al., 2001). Therefore it is possible to speculate

388 that due to progressive peripheral fatigue encountered during the $2 \mathrm{~h}$ constant

389 intensity cycling, there was an increase in the ATP cost of muscle contraction, which

390 in turn might have contributed to the increased $\mathrm{mV}_{2}$. Furthermore, as perception of

391 effort is i) known to be influenced by both mental and muscle fatigue (Pageaux 2014,

392 Pageaux et al., 2015) and ii) a main feature of fatigue (Enoka and Stuart, 1992), the

393 progressive increase in perception of effort during the $2 \mathrm{~h}$ constant load cycling

394 exercise strongly suggests a progressive development of muscle fatigue through the

exercise.

It should be noted that there are some methodological limitations that have to be

398 considered when interpreting the findings of the current study. Firstly, NIRS

399 measurements were made at only one site of the Vastus Lateralis and whether the

400 results hold true for other sites (Koga et al., 2007), or other muscles (Kalliokoski et

401 al., 2006) involved in the cycling action remains to be determined. Secondly the study

402 used continuous-wave NIRS to measure $\mathrm{HbO}_{2}$ and $\mathrm{HHb}$ signals meaning that there

403 are potential confounding factors including an unknown optical path length,

404 absorption and scattering coefficients (Hamaoka et al., 2011). This study used an

405 assumed differential path-length factor to estimate absolute changes in chromophore

406 oxygenation. However, Ferreira et al. (2007) have previously demonstrated that the

407 scattering coefficient can change during exercise, and assuming a constant coefficient

408 can lead to an overestimation of the changes in NIRS variables during exercise.

409 However, it is important to note that the study of Ferreira et al. (2007) investigated 
410 incremental exercise, rather than constant intensity as used in this study. Adipose

411 tissue thickness is a potential major confounder for the NIRS measurements used in the current study (Ferrari et al., 2011). However, there were no repeated measurements used in the current study, and participants were used as their own $\underline{\text { control. In addition, all participants were lean and had an adipose tissue thickness of }}$ less than $12 \mathrm{~mm}$, therefore, the impact of adipose tissue thickness on NIRS measurements are likely to be minimal. Moreover, the use of spatially resolved spectroscopy within the TSI\% measurement is able to account for some of these

418 limitations (Ferrari et al., 2004).

The use of arterial occlusions allowed the quantitative measurement of muscle oxygen consumption independently of blood flow and oxygen delivery. The NIRS data

suggest an increase in muscle blood flow and oxygen consumption over the $2 \mathrm{~h}$

cycling period. However, it is possible that heterogeneity in the NIRS response (Koga

et al., 2007) could have influenced our data and conclusions. The increased blood

flow over the $2 \mathrm{~h}$ cycling could have been accessing regions of the muscle that are not

directly contributing to, or are less efficient in force production. To address this possibility, topographical MRI or fNIRS would be required.

In conclusion, the present study demonstrates that during constant load cycling

430 exercise at $60 \% \mathrm{MMP}$ a $\mathrm{VO}_{2}$ slow component is evident, leading to a resultant

431 reduction in cycling gross efficiency. In vivo Vastus Lateralis mitochondrial oxygen

432 consumption measured via NIRS during arterial occlusions demonstrates concomitant

433 increases in $\mathrm{mV}_{2}$ over time. The increased $\mathrm{mVO}_{2}$ during the $2 \mathrm{~h}$ constant intensity

434 cycling exercise is likely indicative of progressive mitochondrial / contractile 

inefficiency, or the use of the mitochondrial proton motive force for tasks other than ATP production. To further test the relationships between whole-body GE, NIRS derived $\mathrm{mVO}_{2}$, and mitochondrial/contractile efficiency, future studies intervention 438 studies might be considered.

439

\section{Perspectives}

441 Cycling efficiency has been demonstrated to be an important determinant of 442 endurance cycling performance (Coyle et al., 1992; Horowitz et al., 1994; Hopker et 443 al., 2013), which can be improved by endurance training (Hopker et al., 2010).

444 However, to date the underpinning physiological determinants of exercise efficiency 445 are yet to be fully elucidated. Prolonged endurance exercise has been shown to result 446 in reductions in cycling efficiency (Passfield and Doust, 2000), and so therefore 447 provides a method that can be used to investigate its physiological determinants. Over 448 the $2 \mathrm{~h}$ period of constant intensity cycling exercise, the emergence of a $\mathrm{V}_{2}$ slow 449 component is seen to reduce whole body exercise efficiency. With negligible changes 450 in fat metabolism, ventilation, and lactate metabolism it is likely that the main 451 determinant of the pulmonary slow component is the exercising skeletal muscle. 452 Indeed, the increases in the NIRS derived $\mathrm{mV}_{2}$ signal suggest the greater $\mathrm{O}_{2}$ 453 consumption may arise from a combination of both an increased $\mathrm{O}_{2}$ cost of ATP 454 resynthesis, and an increased ATP cost of power production.

455

\section{Acknowledgements}

457 None. 


\section{REFERENCES}

Aaron AE, Seow KC, Johnson BD, Dempsey JA. Oxygen cost of exercise hypernea: implications for performance. J Appl Physiol 1992: 72:1818-1825.

Borg GA. Borg's Perceived Exertion and Pain Scales. Champaign, IL: Human Kinetics 1998. p.49.

Brand MD. Uncoupling to survive? The role of mitochondrial inefficiency in ageing, Exp Gerontol 2000: 35: 811-820. $\square$

Brizendine JT, Ryan TE, Larson RD, Mccully KK. Skeletal Muscle Metabolism in Endurance Athletes with Near-Infrared Spectroscopy. Med Sci Sports Exerc 2013: 45: 869-875.

Cannon DT, Bimson WE, Hampson SA, Bowen TS, Murgatriyd SR, Marwood S, Kemp GJ, Rossiter HB. Skeletal muscle ATP turnover by ${ }^{31} \mathrm{P}$ magnetic resonance spectroscopy during moderate and heavy bilateral knee extension. J Physiol 2014: 5287-99.

Chance B, Dait MT, Zhang C, Hamaoka T, Hagerman F. Recovery from exercise induced desaturation in the quadriceps muscle of elite competitive rowers. Am J Physiol 1992: 262: C766-75.

Chuang M, Ting H, Otsuka T, Sun XG, Chiu FY, Hansen JE, Wasserman K. Muscle deoxygenation as related to work rate. Med Sci Sports Exerc 2002: 34: 1614-1623.

Cohen J. Statistical power analysis for the behavioural sciences $\left(2^{\text {nd }} E d\right)$. Lawrence Erlbaum Associates 1998. p.273-288.

Coyle EF, Sidossis LS, Horowitz JF, Beltz JD. Cycling efficiency is related to the percentage of type I muscle fibres. Med Sci Sports Exerc 1992: 24: 782-788. $\square$

De Blasi RA, Almenrader N, Aurisicchio P, Ferrari M. Comparison of two methods of measuring forearm oxygen consumption $\left(\mathrm{mVO}_{2}\right)$ by near infrared spectroscopy. J Biomed Optics 1997: 2: 171-5.

Enoka RM, Stuart DG. Neurobiology of muscle fatigue. J Appl Physiol 1992: 72: $\underline{1631-48 .}$

Fernstrom M, Bakkman L, Tonkonogi M, Shabalina IG, Rozhdestvenskaya Z, Mattsson CM, Enqvist JK, Ekblom B, Sahlin K. Reduced efficiency, but increased fat oxidation, in mitochondria from human skeletal muscle after 24-h ultraendurnace exercise. J Appl Physiol 2007: 102: 1844-9.

Ferrari M, Mathalib M, Quaresima V. The use of near-infrared spectroscopy in understanding skeletal muscle physiology: recent developments. Philos Transact A Math Phys Eng Sci. 2011: 369: 4577-90. 
Ferrari M, Mottola L, Quaresima V. Principles, techniques, and limitations of near

Hagan RD, Weis SE, Raven PB. Effect of pedal rate on cardiorespiratory responses during continuous exercise. Med Sci Sports Exerc 1992: 24: 1088 -95.

Hagberg JM, Mullin JP, Nagle FJ. Oxygen consumption during constant-load exercise. J Appl Physiol 1978: 45: 381-4.

Hamaoka T, Iwane H, Shimomitsu T, Katsumura T, Murase N, Nishio S, Osada T, Kurosawa Y, Chance B. Noninvasive measures of oxidative metabolism on working human muscles by near-infrared spectroscopy. J Appl Physiol 1996: 81: $1410-7$.

Hamaoka T, McCully KK, Niwayama M, Chance B. The use of muscle nearinfrared spectroscopy in sport, health and medical sciences: recent developments. Philos Transact A Math Phys Eng Sci 2011: 369: 4591-604.

Hopker J, Coleman D, Passfield L, Wiles J. The effects of training volume and intensity on competitive cyclists efficiency. Appl Physiol Nutr Metab 2010: 35: $17-22$.

Hopker J, Jobson SA, Gregson H, Coleman D, Passfield L. Reliability of cycling gross efficiency using the Douglas bag method. Med Sci Sports Exerc 2012: 44: 290-6.

Hopker JG, Coleman DA, Gregson HC, Jobson Sa, Von der Haar T, Wiles J, Passfield L. The influence of training status, age, and muscle fiber type on cycling efficiency and endurance performance. J Appl Physiol 2013: 115: 723-9.

Horowitz JF, Sidossis LS, Coyle EF. High efficiency of type I muscle fibres improves performance. Int J Sports Med. 1994: 15: 152-7.

Kalliokoski KK, Scheede-Bergdahl C, Kjaer M, Boushel R. Muscle perfusion and metabolic heterogeneity: insights from noninvasive imaging techniques. Exerc Sport Sci Rev 2006: 34: 164-70. 
Koga S, Poole DC, Ferreira LF, Whipp BJ, Saitoh T. Ohmae E, Barstow TJ. Spatial heterogeneity of quadriceps muscle deoxygenation kinetics during cycle

Lepers R, Hausswirth C, Maffiuletti N, Brisswalter J, Van Hoecke J. Evidence of neuromuscular fatigue after prolonged cycling exercise. Med Sci Sports Exerc 2000: 32: 1880-6.

Lepers R, Maffuletti NA, Rochette L, Brugniaux J, Millet GY. Neuromuscular fatigue during a long-duration cycling exercise. J Appl Physiol 2002: 92: 1487-93.

\section{Lollgen H, Graham T, Sjogaard G. Muscle metabolites, force, and perceived} exertion bicycling at varying pedal rates. Med Sci Sports Exerc 1980: 12: 345-51.

Mogensen M, Bagger M, Pedersen PK, Fernstrom M, Sahlin K. Cycling efficiency in humans is related to low UCP3 content and to type I fibres but not to mitochondrial efficiency. J Physiol 2006: 571: 669-81.

Nagasawa T. Oxygen consumption in nonexercising muscle after exercise. Int $\mathbf{J}$ Sports Med 200ㅁ: 29: 624-9.

Nioka S, Kime R, Sunar U, Im J, Izzetoglu M, Zhang J, Alacam B, Chance B. A novel method to measure regional muscle blood flow continuously using NIRS kinetics information. Dyn Med 2006: 5: 5.

Pageaux B. The psychobiological model of endurance performance: an effortbased decision-making theory to explain self-paced endurance performance. Sports Med 2014: 44: 1319-20.

Pageaux B, Marcora SM, Rozand V, Lepers R. Mental fatigue induced by prolonged self-regulation does not exacerbate central fatigue during subsequent whole-body endurance exercise. Front Hum Neurosci 2015: 9: 67.

Passfield L, Doust JH. Changes in cycling efficiency and performance after endurance exercise. Med Sci Sports Exerc 2000: 32: 1935-41.

Peronnet F, Massicotte D. Table of nonprotein respiratory quotient: an update. Can J Sport Sci 1991: 16: 23-9. $\square$

Poole D, Gaesser M, Hogan D, Knight D, Wagner P. Pulmonary and leg $\mathrm{VO}_{2}$ during submaximal exercise: implications for muscular efficiency $\square \mathbf{J}$ Appl Physiol. 1992: 72: 805-10.

Poole DC, Barstow TJ, Gaesser GA, Wills WT, Whipp BJ. VO 2 slow component: physiology and functional significance. Med Sci Sports Exerc 1994: 26: 1354-8.

Rossiter HB, Ward SA Kowalchuk JM, Howe FA Griffiths JR, Whipp BJ. 606 
607 on- and off-transients of moderate- and high-intensity exercise in humans. J 608 Physiol 2002: 541: 991-1002.

Sahlin K, Shabalina IG, Mattsson CM, Bakkman L, Fernstrom M, Rozhdestvenskaya Z, Enqvist JK, Nedergaard J, Ekblom B, Tonkonogi M. Ultraendurance exercise increases the production of reactive oxygen species in isolated mitochondria from human skeletal muscle. J Appl Physiol 2010: 108: 780-787.

Tonkonogi M, Harris B, Sahlin K. Mitochondrial oxidative function in human saponin-skinned muscle fibres: effects of prolonged exercise. J Physiol 1998: 510: 279-86.

Van Beekvelt MC, Colier WN, Wevers RA, Van Engelen BG. Performance of near-infrared spectroscopy in measuring local $\mathrm{O}_{2}$ consumption and blood flow in skeletal muscle. J Appl Physiol 2001: 90: 511-19.

Whipp BJ, Wasserman K. Efficiency of muscular work. J Appl Physiol 1969: 26: 644-8. 


\section{FIGURE LEGENDS}

Figure 1. Overview of the protocol and timing of measurements used during visit 2.

Figure 2. A typical NIRS trace showing $\mathrm{HbO}_{2}, \mathrm{HHb}$ and $\mathrm{tHb}$ signals during a $20 \mathrm{~s}$ occlusion of the Vastus Lateralis muscle during cycling. Trace data has been filtered using a 10-point average. Shaded area identifies the $\underline{3 \mathrm{~s}}$ period of data selected for the calculation of $\mathrm{m} \dot{\mathrm{V}} \mathrm{O}_{2}$.

Figure 3. Changes in a.) Gross Efficiency, b.) RER, c.) $\dot{\mathrm{V}} \mathrm{O}_{2}$, d.) $\dot{\mathrm{V}} \mathrm{CO}_{2}$, e.) Ventilation, f.) Heart rate, g.) Blood lactate, h.) Rating of perceived exertion during 2 $\mathrm{h}$ constant load cycling exercise. Values are means \pm SEM for figures a-f. * $=$ significantly different from $\min 6 . \#=$ significantly different from $\min 30 .^{\wedge}=$ significantly different from min 60. \$ significantly different from min 90.

Figure 4. Changes from baseline in a) $\Delta \mathrm{HbO}_{2}$, b) $\Delta \mathrm{HHb}$, c) $\Delta \mathrm{tHb}$ and d) $\Delta \mathrm{TSI} \%$ during $2 \mathrm{~h}$ constant load cycling exercise. Values are means \pm SEM. $*=$ significantly higher than 5 min. ${ }^{\wedge}=$ significantly higher than 5 and $30 \mathrm{~min}$.

Figure 5. $\mathrm{mV}_{2}$ response from $2 \mathrm{~h}$ cycling constant load cycling exercise. a) Time course of $\mathrm{m} \dot{V O}_{2}$ response during $2 \mathrm{~h}$ constant load cycling exercise, b) half time of oxygenation recovery and c) reoxygenation rate following release of 5 min occlusion pre and post exercise. Values are means \pm SEM.

Figure 6. Sprint power output at cadences of 60,90 and 120 rev.min ${ }^{-1}$ pre- and post$2 \mathrm{~h}$ constant load cycling exercise. Values are means \pm SEM. * significant main effect of time. 


\section{Overview of the protocol and timing of measurements used during visit 2.} $297 \times 209 \mathrm{~mm}(300 \times 300$ DPI $)$ 


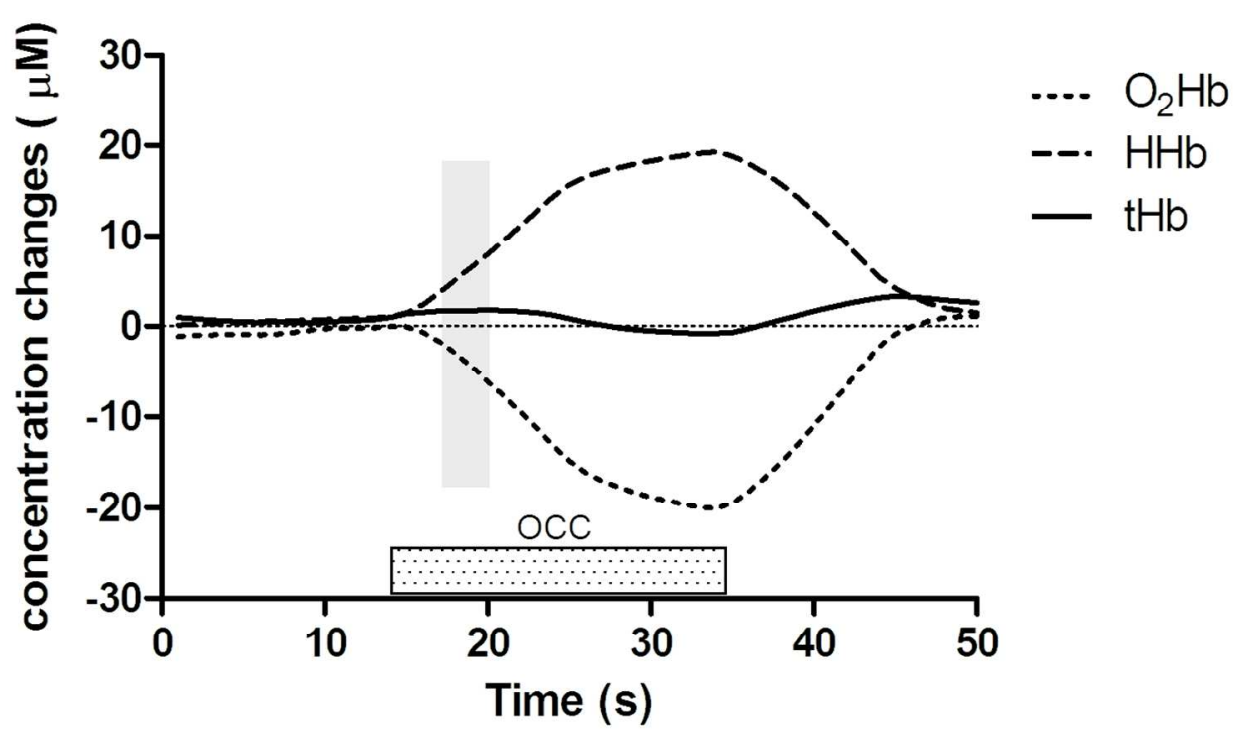

A typical NIRS trace showing $\mathrm{HbO}_{2}, \mathrm{HHb}$ and thb signals during an occlusion to the Vastus Lateralis muscle during cycling. Trace data has been filtered using a 10-point average. Shaded area identifies the period of data selected for the calculation of $\mathrm{mVO}_{2}$. $121 \times 73 \mathrm{~mm}(300 \times 300 \mathrm{DPI})$ 
Changes in a.) Gross Efficiency, b.) RER, c.) $\mathrm{VO}_{2}$, d.) $\mathrm{VCO}_{2}$, e.) Ventilation, f.) Heart rate, g.) Blood lactate, h.) Rating of perceived exertion during $2 \mathrm{~h}$ constant load cycling exercise. Values are means \pm SD for figures a-f. ${ }^{*}=$ significantly different from $\min 6$. \# = significantly different from $\min 30 . \wedge=$ significantly different from min 60. \$ significantly different from min 90. $148 \times 201 \mathrm{~mm}(300 \times 300 \mathrm{DPI})$ 

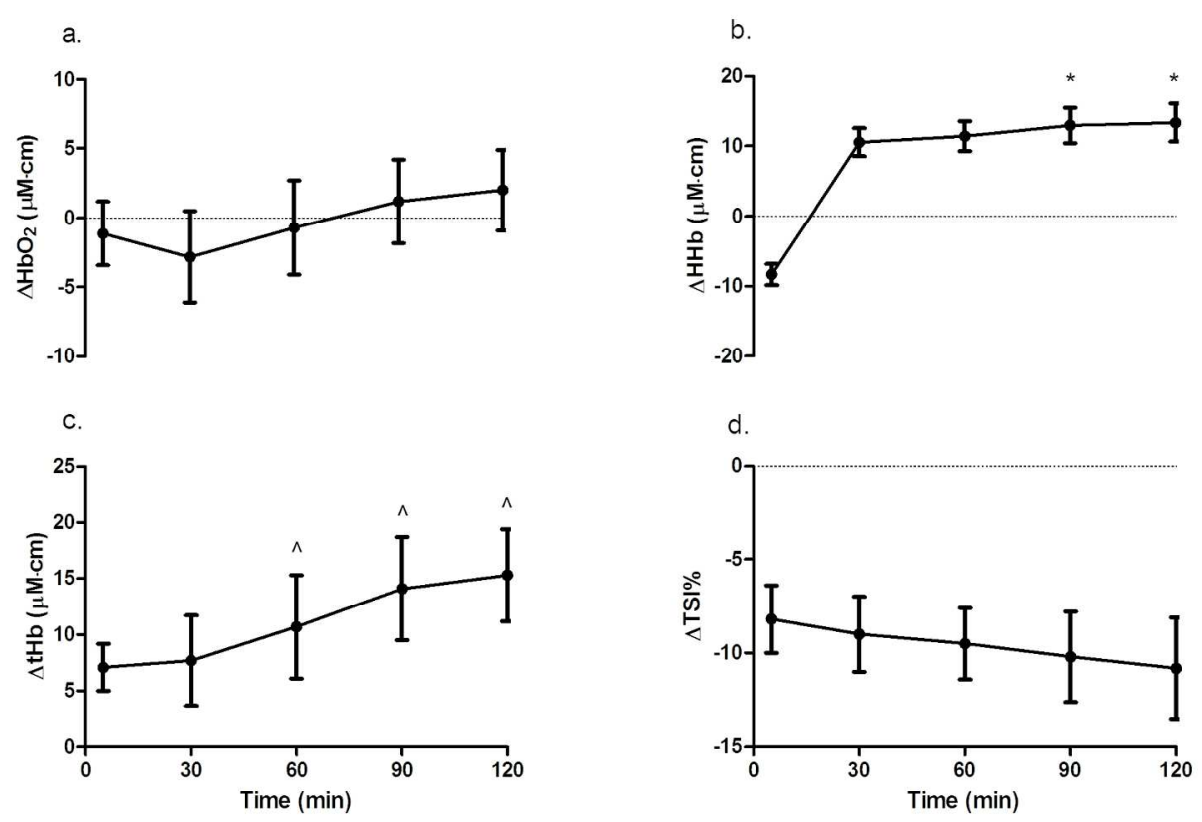

Mean values for a) $\Delta \mathrm{HbO}_{2}$, b) $\Delta \mathrm{HHb}$, c) $\Delta \mathrm{tHb}$ and d) $\Delta \mathrm{TSI} \%$ during $2 \mathrm{~h}$ constant load cycling exercise. Values are means \pm SEM. $*$ = significantly higher than $5 \mathrm{~min} . \wedge=$ significantly higher than 5 and $30 \mathrm{~min}$. $181 \times 124 \mathrm{~mm}(300 \times 300 \mathrm{DPI})$ 

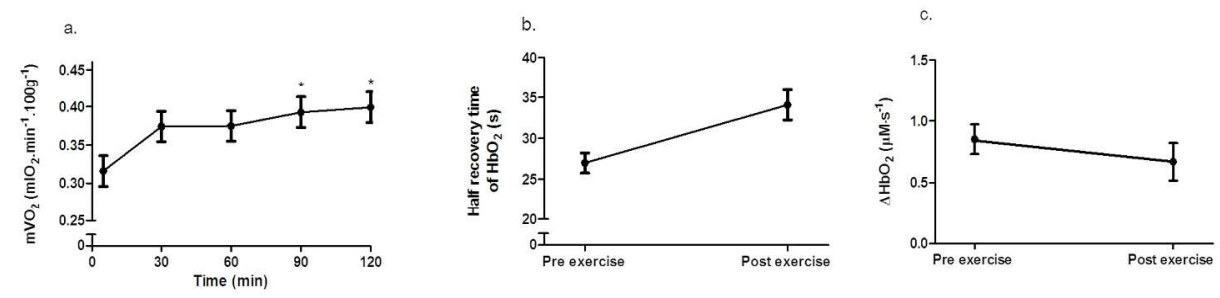

mVO2 response from $2 \mathrm{~h}$ cycling constant load cycling exercise. a) Time course of mVO2 response during 2 $\mathrm{h}$ constant load cycling exercise, b) half time of oxygenation recovery and c) reoxygenation rate following release of 5 min occlusion pre and post exercise. Values are means \pm SEM. $178 \times 50 \mathrm{~mm}(300 \times 300 \mathrm{DPI})$ 


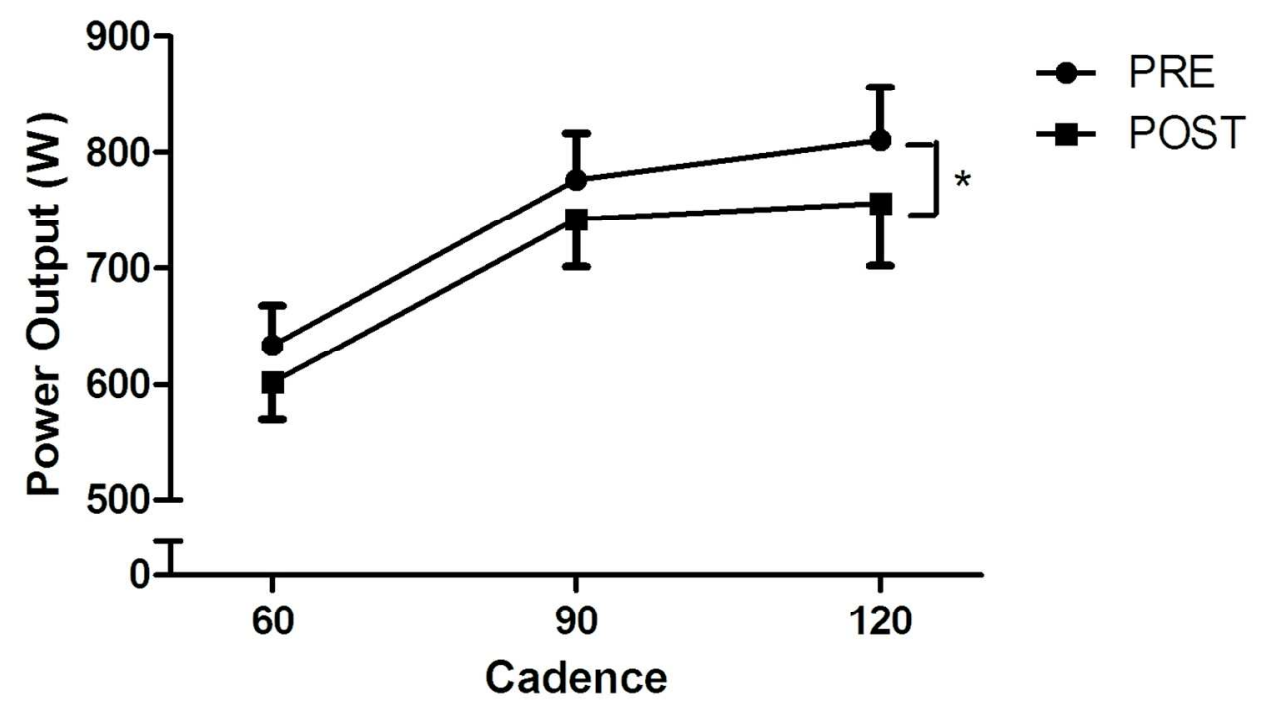

Sprint power output at cadences of 60,90 and 120 rev. $\mathrm{min}^{-1}$ pre- and post- $2 \mathrm{~h}$ constant load cycling exercise. Values are means \pm SEM. * significant main effect of time. $122 \times 73 \mathrm{~mm}(300 \times 300 \mathrm{DPI})$ 